\title{
PRÍNCIPE LIEV NIKOLÁIEVITCH MÍCHKIN ("O IDIOTA", FIÓDOR DOSTOEVSKY) E A SÍNDROME DE PERSONALIDADE INTERICTAL NA EPILEPSIA DO LOBO TEM PORAL
}

\author{
Leonardo Cruz de Souza ${ }^{1}$, Mirian Fabíola Studart Gurgel Mendes²
}

\begin{abstract}
RESUM 0 - A obra do romancista russo Fiódor Dostoevsky (1821-1881), além de seu extraordinário valor literário, reveste-se de importância especial para neurologistas e epileptologistas. 0 escritor, que era portador da enfermidade, transmitiu através de seus textos o universo do epiléptico e a maneira como esse é percebido pela sociedade. Seus livros tiveram grande influência na maneira como a cultura ocidental percebe a doença. 0 romance "O Idiota" tem como protagonista o Príncipe Liev Nikoláievitch Míchkin, um epiléptico com personalidade marcante. Considerando a proposta feita por Geschwind-Waxman (1975) de síndrome de personalidade interictal na epilepsia do lobo temporal, este artigo pretende discutir as alterações comportamentais no paciente epiléptico a partir de Míchkin, personagem principal de "O Idiota", de Fiódor Dostoevsky.
\end{abstract}

PALAVRAS-CHAVE: epilepsia temporal, Dostoevsky, síndrome de personalidade interictal, síndrome de Geschwind-Waxman.

\begin{abstract}
Prince Liev Nikoláievitch Míchkin ("The Idiot", Fiódor Dostoevsky) and the interictal personality syndrome of temporal lobe epilepsy

ABSTRACT - Russian romancist Fiódor Dostoevsky's composition, besides its extraordinary literary value, has a special importance for neurologists and epileptologists. The writer, who suffered of epilepsy, transmitted in his texts the epileptic's universe and how the pacient is perceived by the society. His novels had great influence on how epilepsy is perceived by western culture. The romance "The Idiot" has as protagonist Prince Liev Nikoláievitch Míchkin, a epileptic with remarkable personality. Considering the propose made by Geschwind-Waxman (1975) of a interictal personality syndrome in temporal lobe epilepsy, this article intends to discuss the behavioral alterations in epileptic patient, from Míchkin, the main character in Fiódor Dostoevsky's "The Idiot".
\end{abstract}

KEY WORDS: temporal epilepsy, Dostoevsky, interictal personality syndrome, Geschwind-Waxman syndrome.

Aparentemente díspares e imiscíveis entre si, arte e ciência compartilham em suas naturezas ampla interface de similaridades: ambas só têm sentido quando situadas dentro de contexto histórico específico; ambas podem abordar o mesmo fenômeno, a mesma verdade, identificando-os, descrevendo-os e interpretando-0s, embora de maneira essencialmente distintas. A relação entre arte e ciência pode ser entendida como de complementaridade, e não de simples antagonismo. A obra do romancista russo Fiódor Mikháilovitch Dostoevsky (1821-1881) é emblemática em ilustrar o quanto a arte pode complementar à ciência o nosso entendimento da epilepsia. Os romances do autor, dentre os quais se destacam

\begin{abstract}
"Crime e Castigo", "Os Irmãos Karamázovi" e "O Idiota", são marcados pela excelência na descrição psicológica dos personagens, pelo profundo sentimento religioso e pelas reflexões filosóficas. Há, ainda, um outro traço recorrente nos textos do escritor: a epilepsia. 0 escritor, que sofreu da enfermidade durante várias décadas, traduziu em sua literatura 0 universo do epiléptico, sua personalidade e a maneira como é percebido pela sociedade. Por isso, dada a repercussão de seus livros, Dostoevsky teve grande influência no modo como a epilepsia é percebida no ocidente, sendo objeto de dedicado estudo de epileptologistas proeminentes com Gastaut e Alajounine. Alajounine ${ }^{1}$ sublinha o interesse
\end{abstract}

${ }^{1}$ Especializando em Neurologia do Hospital Madre Teresa, Belo Horizonte MG, Brasil; ${ }^{2}$ Neurologista e Neurofisiologista do Hospital Madre Teresa, Mestre em Neurologia pela Faculdade de Medicina da Universidade de São Paulo, Ribeirão Preto SP, Brasil.

Recebido 24 Novembro 2003. Aceito 19 Fevereiro 2004.

Dr. Leonardo Cruz de Souza - Hospital Madre Teresa - Avenida Raja Gabaglia 1002 - 30380-090 Belo Horizonte M G - Brasil. E-mail: leocruzsouza@uai.com.br 
na leitura dos textos do escritor russo porque neles estão projetadas as experiências pessoais do autor (descritas com minúcia e sofisticação) e porque sua literatura teve papel fulcral na concepção ocidental da epilepsia.

0 presente estudo pretende discutir as alterações comportamentais no paciente epiléptico, a partir da personalidade do Príncipe Liev Nikoláievitch Míchkin, personagem principal de "O Idiota", de Dostoevsky.

\section{EPILEPSIA E ALTERAÇÕES COMPORTAMENTAIS}

Poucas afecções sofreram tanta estigmatização, preconceito e incompreensão quanto a epilepsia. Em minucioso artigo, Ozer ${ }^{2}$ relata como a epilepsia e o epiléptico foram enxergados ao longo da história, desde os tempos bíblicos até os filmes e seriados televisivos atuais. A autora aponta pelo menos quatro maneiras pelas quais os pacientes epilépticos foram estigmatizados: como endemoniados, como santos, como gênios, como portadores de depressão suicida. 0 conceito de uma personalidade epiléptica remonta, portanto, há vários séculos de história.

Contudo, foi a partir de meados do século XIX, quando a epilepsia passou a ser cientificamente estudada, que foram feitas as primeiras correlações entre epilepsia e alterações comportamentais. Segundo Devinsky e Najjar. ${ }^{3}$, Gowers reconheceu, em 1885, que muitos epilépticos tinham personalidades dentro da normalidade, mas que muitos outros desenvolviam mudanças comportamentais interparoxísticas. Ainda, segundo Devinsky et al. ${ }^{3}$, Kinnier Wilson e Sjobring, em trabalhos separados, no início do século XX, apontaram a existência de alterações comportamentais "negativas" no paciente epiléptico. Em 1923, Kraeplin 4 observou que mais da metade dos pacientes epilépticos apresentava marcantes características de personalidade, dentre elas lentificação dos processos mentais, prolixidade, circunstancialidade e irritabilidade, além de alguns traços "positivos", tais como tranqüilidade, modéstia, honestidade e religiosidade. Finalmente, em 1951, Gibbs ${ }^{5}$ relata a associação entre mudanças de comportamento e epilepsia do lobo temporal. Em 1955, Gastaut ${ }^{6}$ publicou um estudo sobre as alterações comportamentais em pacientes com epilepsia do lobo temporal, salientando que essas eram opostas àquelas observadas na síndrome de Kluver-Bucy.

Os estudos de Norman Geschwind e de Stephen Waxman $^{7}$ sugeriram, em 1975, a existência de um conjunto de características de personalidade semelhantes em pacientes com epilepsia do lobo temporal. A proposta sindrômica (que mais tarde foi denominada de síndrome de Geschwind-Waxman) reunia pacientes com epilepsia do lobo temporal que apresentavam: alterações do comportamento sexual (hipossexualidade), religiosidade e tendência a escrever compulsivamente (hipergrafia). A seguir, buscou-se identificar e quantificar tais características de personalidade. Para tanto,
Tabela 1. Características de personalidade inqueridas no inventário de BearFedio.

\begin{tabular}{ll}
\hline - Agressividade & - Interesse sexual alterado \\
- Viscosidade & - Circunstancialidade \\
- Senso de destino pessoal & - Culpa \\
- Dependência emocional; & - Hipergrafia \\
passividade & - Hipo ou hipermoralismo \\
- Depressão & - Interesses filosóficos \\
- Religiosidade & - Paranóia \\
- Comportamento obsessivo & - Irritabilidade \\
- Elação, euforia & - Emocionalidade \\
\hline
\end{tabular}

Bear e Fedio ${ }^{8}$ conceberam um inventário, que consiste em 90 questões referentes a 18 traços de personalidade supostamente característicos da epilepsia do lobo temporal, além de 10 outras extraídas do M innesota Multiphasic Personality Inventory Scale (Tabela 1). 0 inventário foi aplicado a diversos grupos de pacientes em vários estudos clínicos que mostraram que pacientes com epilepsia (tanto as formas generalizadas quanto as do lobo temporal) atingiam maiores pontuações que controles normais, embora não distinguisse pacientes epilépticos de pacientes psiquiátricos ${ }^{3}$.

Devido a limitações metodológicas dos estudos, o inventário não teve a sua aplicabilidade validada a grandes e diversas populações e, assim, a existência de uma síndrome comportamental foi questionada ${ }^{3,9,10}$, embora ainda se defenda que determinadas manifestações comportamentais notadamente 0 interesse por temas filosóficos e religiosos, a hipergrafia, alterações no comportamento sexual e a agressividade - são mais comuns em pacientes com epilepsia do lobo temporal9,11,12. Para Geschwind ${ }^{11}$, a presença da síndrome não é necessariamente patognomônica de um foco epiléptico no lobo temporal, assim como se admite que as alterações comportamentais possam ser encontradas em outras formas de epilepsias. No mesmo trabalho, contudo, 0 autor ressalta que o diagnóstico da síndrome deve motivar a investigação eletroencefalográfica do paciente.

Ao empregar o inventário de Bear-Fedio, Weiser ${ }^{13}$ observou diversas associações entre as determinadas características da personalidade (Tabela 2). A relação entre a epilepsia do lobo temporal e alterações de comportamento permanece assunto controverso na literatura ${ }^{14}$.

\section{A AURA DO PRAZER}

De acordo com Gastaut ${ }^{15}$, os estudos de J. Hughlings Jackson entre 1876 e 1890 propuseram a distinção das auras psíquicas em dois grupos: intelectuais ou emocionais. Para Jackson, as auras emocionais estariam restritas a sensações desagradáveis, como medo e angústia. Tanto Jackson quanto os estudiosos das auras psíquicas que se seguiram a ele não 
Tabela 2. Associações entre características de personalidade, segundo Weiser ${ }^{13}$.

- Humor deprimido e focos frontais

- Todos os traços são mais comuns em pacientes com focos frontais

- Circunstancialidade e hipermoralismo mais comuns em foco temporo-límbico

- Humor deprimido e hipermoralismo mais comuns em foco direito

- Humor deprimido e hipermoralismo mais comuns em foco direito

- Religiosidade, hipergrafia e comportamento sexual alterado em foco esquerdo

- Emocionalidade e sexo feminino

- Hipermoralismo e sexo masculino

- Pacientes desempregados e desqualificados são mais dependentes e passivos

- Pacientes canhotos têm a sexualidade afetada com maior freqüência

- Crises que se iniciaram antes dos 5 anos correlacionam-se mais com humor deprimido

- Pacientes com antecedentes urbanos comumente têm mais humor deprimido

fazem referência ao fenômeno como a experiência de uma sensação agradável.

Morgan ${ }^{16}$ define a aura de êxtase como infreqüentes fenômenos da epilepsia do lobo temporal, caracterizados por intensa sensação de prazer, alegria e contentamento, sendo observados em duas formas. A primeira ocorre em pacientes que têm um súbito lapso da consciência, com sentimento de prazer inexplicável que não é seguido de nenhuma outra forma de manifestação epiléptica. A segunda forma ocorre antes do episódio epiléptico generalizado.

Como assinala Gastaut ${ }^{15}$, desde 0 século XIX os epileptologistas admitem a ocorrência de fenômenos psíquicos como componentes das crises epilépticas do lobo temporal. As manifestações psíquicas mais freqüentes são sensações de medo, ansiedade, terror e pavor. Segundo Gastaut, o conceito de aura extática surgiu a partir de meados do século XX, quando foi descoberta a epilepsia do lobo temporal. Desde então, vinculou-se a descrição referida por Dostoevsky da sensação prazerosa que antecedia as crises com a epilepsia temporal. Gastaut concluiu que os textos do autor russo e a sua conhecida biografia contribuíram para a formulação do conceito de aura de prazer, o qual não foi devidamente acompanhado das necessárias demonstrações científicas de sua existência. Fundamentado em sólidas pesquisas bibliográficas e biográficas, Gastaut afirma que o romancista russo sofria de crises generalizadas, enão parciais complexas.

0 tema é retomado por Voskuil ${ }^{17}$ que apresentou dados que sustentam a hipótese de que Dostoevsky era portador de crises parciais complexas com ataques predominantemente noturnos e, revendo casos publicados de aura extática, considera que 0 escritor russo efetivamente a experimentava. Após 0 trabalho de Voskuil, Gastaut ${ }^{18}$ fez novas considerações acerca da epilepsia de Dostoevsky e afirma que o escritor russo provavelmente tinha uma lesão temporal de pequena magnitude (que não lhe provocava manifestações no período interictal, mas que poderia levar à aura temporal antes das crises), além de uma predisposição constitucional à epilepsia, o que levava a generalizações secundárias a cada episódio epiléptico. Assim, como assinala Yacubian ${ }^{19}$, Gastaut sugere um conceito unicista da epilepsia de Dostoevsky: as crises teriam como substrato uma provável lesão temporal e uma importante predisposição genética; ocorreriam generalizações secundárias rápidas em cada crise.

Diversos casos de epilepsia com aura de prazer são relatados na literatura ${ }^{16,20-23}$, dentre os quais se destaca 0 relatado por Cirignotta et al.$^{20}$, o primeiro a registrar por eletroencefalografia a descarga epiléptica no lobo temporal.

\section{PRÍNCIPE LIEV NIKOLÁIEVITCH MÍCHKIN \\ E A SÍNDROME DE PERSONALIDADE INTERICTAL NA EPILEPSIA DO LOBO TEMPORAL}

0 romance 0 ldiota ${ }^{24,25}$ (1868) inicia-se com a chegada a São Petersburgo de Liev Nikoláievitch Míchkin, que vinha da Suíça após prolongado tratamento de sua enfermidade, a epilepsia. A trama desenrola-se a partir do envolvimento do personagem, último representante de uma linhagem nobre (daí ser um Príncipe), com a família do General lepántchin. No processo de criação de Míchkin - um dos personagens mais marcantes da literatura universal -, Dostoevsky intencionalmente elabora um personagem que aglutina em si um ideal de perfeição fundamentado em Dom Quixote, de Cervantes, e na figura de Cristo. Míchkin, então, contrasta-se fortemente com a sociedade em que está inserido; com seu humanismo autêntico, deflagra as mais variadas reações ao seu redor, sejam elas de comiseração, de amor, de ódio, de respeito. A leitura dessa obra reveste-se de especial interesse para os epileptologistas. Em M íchkin, de maneira sublime, estão projetadas as experiências a as vivências do próprio autor. A personalidade do Príncipe Míchkin guarda numerosas interseções com a proposta sindrômica de Geshwind, como procuraremos demonstrar a seguir.

\section{Hipossexualidade}

Ainda no trem que o trouxera a São Petersburgo, Míchkin mantém o seguinte diálogo com Rogójin, que acabara de conhecer. 
“- E quanto ao sexo feminino, príncipe, és um grande apreciador? Dize antes!

- Eu,n-n-não! É que eu... Talvez o senhor não saiba, mas por causa de minha doença congênita nunca conheci mulher!"

No trecho assinalado, Míchkin (que então contava com 27 anos) atribui à doença a sua castidade. Parece-nos que este comportamento não é resultado de impotência sexual propriamente, mas de um desinteresse pela atividade sexual em si. Mesmo ao aproximar-se afetivamente de Aglaia e de Nastássia Filíppovna, Míchkin parece impelido por um amor idealizado, quase platônico.

\section{Hipergrafia}

A pós desembarcar na estação, Míchkin dirige-se à casa da família do General lepántchin. É o primeiro contato de uma relação que se estreita ao longo de todo o romance. Embora tenha parentesco com a esposa do General, M íchkin é um desconhecido para essa família. Na primeira conversa com 0 General, passa-se o seguinte diálogo:

\section{“ (...) - Então sabe ler e escrever corretamente? Oh, muito. \\ Ótimo, e a letra?}

A letra é magnífica. Eis aí onde, é de crer, eu tenho talento; nisso eu sou simplesmente um calígrafo. Deixe que eu escreva agora mesmo alguma coisa para teste - disse 0 príncipe com entusiasmo."

A seguir, o príncipe escreve uma mesma frase com diferentes caracteres (dentre eles, russos medievais, ingleses e franceses). Eis a impressão que Míchkin tem do que acabara de redigir:

“- (...)Veja mais esses caracteres belos e originais (...) É a letra russa, letra de escrivão, ou, se quiser, de escrivão militar. É assim que se lavra papel oficial endereçado a uma pessoa importante, também com caracteres redondos, magníficos, em negrito, em negro, mas com um gosto notável. (...) aqui aparece toda a alma da escrituração militar: a gente tem vontade de soltar-se, o talento pede passagem, mas a gola militar está fortemente presa a um gancho, a disciplina aparece até na caligrafia, uma maravilha! (...)"

A reação do General não é menos apaixonada:

“(...) o senhor, meu caro, não é simplesmente um calígrafo, o senhor, meu caro, é um artista (...)"

Esse talento para a caligrafia pode ser entendido como hipergrafia, embora esta se refira mais especificamente à tendência a escrever copiosamente. É de se observar que tal habilidade de Míchkin valeu-lhe um emprego como escrivão pessoal do General.

\section{Melancolia}

São muitas as passagens que expressam sentimentos melancólicos em Míchkin. De modo recorrente, tais emoções mesclavam-se a idéias auto-punitivas (culpa exacerbada) e a baixa auto-estima. Nos trechos que se seguem, estão exemplificados momentos de melancolia vividos pelo personagem:

"Estava em uma tensão angustiante e intranqüilo e ao mesmo tempo sentia uma necessidade inusual de estar só. Queria estar só e entregar-se a essa tensão sofredora de modo absolutamente passivo, sem procurar a mínima saída."

"O príncipe estava muito contente por finalmente o terem deixado só; ele desceu a varanda, atravessou o caminho e entrou no parque; queria ponderar e decidir um passo a ser dado. Mas esse "passo" não era daqueles que se ponderam e sim daqueles que justamente não se ponderam e simplesmente se decide por ele: súbito sentiu uma terrivel vontade de largar tudo ali e voltar para o lugar de onde viera, para algum lugar mais distante, para os confins, partir agora mesmo inclusive sem se despedir de ninguém. Pressentia que se permanecesse ali, ao menos por alguns dias, forçosamente afundaria nesse mundo de modo irreversivel, e mais tarde esse mesmo mundo acabaria sendo o seu destino. Mas ele não meditou nem dez minutos e resolveu imediatamente que "era impossível" fugir, que isso seria quase uma pusilanimidade, que tinha problemas pela frente e agora não tinha nenhum direito de fugir à sua solução ou ao menos de deixar de empreender todos os esforços para resolvê-los. Voltou para casa com esses pensamentos e é pouco provável que tenha passeado sequer quinze minutos. Nesse momento estava totalmente infeliz."

"Às vezes Ihe dava vontade de ir para algum lugar, sumir inteiramente dali, e gostaria até de um lugar sombrio, deserto, contanto que ficasse só com os seus pensamentos e que ninguém soubesse onde ele se encontrava"

“- (..) disse Rogójin - (...) por que não respondeste nada a ela? "Tu és feliz ou não"?

Não, não, não! - exclamou o príncipe com um sofrimento infinito."

\section{Caráter anti-social}

Embora tenha mantido relações com amplo grupo de pessoas, Míchkin, em diversos momentos, demonstra preferir a solidão à companhia dos outros. Nos seguintes trechos, expressam-se tal tendência e a sua atração pelas crianças:

"Eu sou insociável, e é possivel que fique muito tempo sem visitá-las.(as filhas do General)"

"No entanto existe aí apenas uma verdade; eu realmente não gosto de estar com adultos, com pessoas, com grandes

- isso eu notei faz tempo -, não gosto porque não sei. 0 
que quer que eles conversem comigo, por mais bondosos que sejam comigo, mesmo assim a companhia deles é sempre pesada para mim sabe-se lá por quê, e eu fico terrivelmente feliz quando posso sair o mais rápido para a companhia dos companheiros, e meus companheiros sempre foram as crianças, não porque eu sempre fui uma criança e sim porque as crianças sempre me atraíram."

Durante toda a trama, a ética e o humanismo de Míchkin contrastam-se fortemente com a sociedade que o rodeia. Essa contraposição adquire um caráter anti-social - Míchkin repudia o que há de anti-ético e imoral no meio social. Daí, ser o príncipe atraído pelo universo infantil, pela pureza, pela doce ingenuidade das crianças.

\section{Baixa auto-estima}

Idéias negativas acerca de sua própria pessoa recorrentemente afligem Míchkin. 0 sentimento de inferioridade vincula-se à culpa excessiva e ao humor depressivo, compondo um perfil que caracterizará o príncipe durante toda a estória, como é exemplificado a seguir:

“(...) Não dê importância (...) vou me retirar agora. Eu sei que eu... fui ofendido pela natureza. Passei vinte e quatro anos doente, do nascimento aos vinte quatro anos. Interprete isso como de alguém doente também neste momento. (...) em sociedade eu estou sobrando (...) Eu não tenho modos convenientes, não tenho senso de medida; eu tenho palavras diferentes e não pensamentos correspondentes, e isso é uma humilhação para esses pensamentos. É por isso que eu não tenho o direito... e ainda por cima sou cheio de cismas, eu... eu estou convencido de que nesta casa não poderão me ofender e gostam de mim mais do que eu mereço (...)"

"Eu sempre temo comprometer com meu aspecto ridículo o pensamento e a idéia principal. Eu tenho gesto sempre oposto, e isso provoca o riso e humilha a idéia. Tampouco tenho senso de medida, e isso é o principal; é até o mais importante... Sei que para mim é melhor ficar sentado e calado. Quando teimo e calo, pareço até muito sensato, e ainda por cima pondero."

\section{Culpa excessiva}

Ideações de culpa - na maioria das vezes injustificada e exacerbada - assolavam o príncipe com freqüência tal a originar nele sentimentos melancólicos e de baixa auto-estima. A passagem seguinte ilustra tal característica de Míchkin.

"Eu devia ter esperado e feito a proposta amanhã a sós com ele - pensou imediatamente o príncipe - , mas pelo visto agora não vou conseguir consertar! Sim, eu sou um idiota, um verdadeiro idiota!" - decidiu ele de si para si num acesso de vergonha e excepcional amargura."

\section{Hiperreligiosidade}

Em vários episódios da história, Míchkin defende de modo inflamado a fé genuinamente cristã, a crença em Deus e na Sua graciosa Providência. Repele com veemência a depravação moral do homem, 0 ateísmo e a corrupção que descaracterizou a igreja na Rússia. Os trechos em que o príncipe expressa sua fé em Deus constituem pontos altos da literatura de Dostoevsky. Aqui o escritor russo projeta o forte sentimento religioso que impulsionou sua vida. A passagem ora separada é o diálogo de Míchkin com Parfen Rogojín, no qual o príncipe refere-se ao encontro que teve com uma camponesa, que, com o filho no colo, Ihe testemunha a fé na misericórdia divina.

“ (...) (a camponesa) expressou esse pensamento tão profundo, tão sutil e verdadeiramente religioso, esse pensamento em que toda a essência do Cristianismo foi expressa de uma vez, isto é, todo o conceito de Deus como nosso pai querido e da alegria de Deus com o homem como a alegria do pai com o seu filho querido - a idéia central de Cristo! (...) escuta Parfen, há pouco me fizeste uma pergunta e eis a minha resposta: a essência do sentimento religioso não se enquadra em nenhum juízo, em nenhum ato ou crime ou nenhum ateísmo; aí há qualquer coisa diferente e que vai ser sempre diferente. Aí há qualquer coisa sobre a qual irão escorregar eternamente os ateísmos e da qual irão dizer eternamente coisas diferentes."

\section{Outras características}

0 príncipe Míchkin demonstra também outras características que o aproximam da proposta sindrômica de Geshwind.

A circunstancialidade (viscosidade) e a prolixidade manifestam-se nos longos discursos do personagem, sobre os mais diferentes temas, desde lembranças de sua infância, suas viagens, até as reflexões filosófico-religiosas. 0 interesse pelos temas filosóficos e religiosos também é marcante em Míchkin, que ao longo da novela expõe seus pensamentos acerca da religiosidade, reflete sobre a questão da culpa e sobre as motivações morais do homem - nesses momentos, sobressaía-se mais uma peculiaridade do príncipe que 0 aproxima da proposta de Geshwind: o hipermoralismo, que é sublinhado pelo contraste com a impulsividade de Rogojín e a ganância de Gânia. A emocionalidade de Míchkin permeia toda a obra e, uma vez mais, Dostoevsky a ressalta através do contraponto com as personalidades de Nastássia Filipóvna e, especialmente, com a de Aglaia lepántchkin, notória por sua fleuma impenetrável. A sensibilidade com que o príncipe reage aos diversos episódios com que se depara reforçam no leitor a impressão da complexa delicadeza da alma de Míchkin, 0 que era a clara intenção do romancista ao compor o perso- 
nagem. Há ainda, duas outras características da síndrome que reforçam a emocionalidade de Míchkin: a sua passividade e a dependência que marca sua relação com os mais próximos. Pode-se subtrair das reflexões de Míchkin acerca dos dilemas morais do homem um profundo sentimento de destino pessoal, o que o torna ainda mais atribulado perante os impasses éticos que lhe são defrontados.

Permitindo-nos uma cogitação ainda maior, não podemos estabelecer a localização do foco epiléptico de Mìchkin, a partir das informações extraídas da obra e do trabalho de Weiser ${ }^{13}$. Enquanto a religiosidade, a hipergrafia e a hipossexualidade sugeririam um foco epiléptico em hemisfério esquerdo, o humor deprimido e o hipermoralismo indicariam um foco direito.

Embora não constitua um elemento da síndrome, é pertinente que nos remetamos à célebre descrição da aura de prazer do príncipe. A aura de Míchkin - trecho em que a genialidade de Dostoevsky se revela plenamente - foi alvo de dedicado estudo dos epileptologistas. Sem dúvida alguma, como assinala Gastaut ${ }^{15}$, a passagem da aura de êxtase fomentou a suposição de que a epilepsia de Dostoevsky fosse uma crise parcial complexa com um foco temporal, além de contribuir em muito para a concepção ocidental da aura epiléptica.

\section{FIÓDOR DOSTOEVSKI E A EPILEPSIA}

0 romance 0 Idiota está repleto de passagens que nos remetem à própria biografia de Dostoevsky; a cena de execução descrita por Míchkin foi aquela experimentada pelo escritor russo ao ser condenado por conspiração contra Czar (pena que foi suspensa nos instantes finais, após o que o romancista foi enviado a uma prisão na Sibéria); o fascínio de Míchkin pelo quadro de Hans Holbein, em um museu de Genebra, aconteceu com Dostoevsky quando ele visitou a cidade ${ }^{26}$. A epilepsia de Míchkin também nos leva imediatamente à biografia do escritor russo, 0 qual teve sua vida profundamente impactada pela enfermidade - em seu artigo, Gastaut ${ }^{15}$ afirma que 0 romancista teve mais de 400 crises epilépticas em um período de 40 anos. Importantes biografias de Dostoevsky ${ }^{26-29}$ também são pródigas em ilustrar o quanto sua vida e sua obra tiveram a marca indelével da doença. A propósito, Sigmund Freud escreveu um ensaio (Dostoevsky e o parricídio ${ }^{30}$ ) em que dá uma explicação fantasiosa para a epilepsia do escritor. Segundo Freud, Dostoevsky desejou durante anos a morte do pai, o qual sempre foi uma figura opressora e dominadora. Quando se dá o falecimento do pai do escritor, em 1839 - assassinado pelos camponeses de sua propriedade - deflagra-se no jovem Dostoevsky um processo psíquico de auto-punição, que resultaria na sua enfermidade. As crises do escritor, portanto, seriam de natureza histérica, e não epiléptica.

Escapa aos objetivos deste estudo aprofundar-se sobre a doença de Dostoevsky. Tão fascinante como perceber em Míchkin traços que caracterizam a proposta sindrômica de
Geshwind, seria tentar perscrutar na biografia de Dostoevsky elementos dessa síndrome - destacam-se na personalidade do escritor russo a hipergrafia, a melancolia, a emocionalidade, a hiperreligiosidade, 0 hipermoralismo, o senso de destino pessoal e 0 interesse por assuntos filosóficos. Contudo, não faríamos essa identificação sem um profundo sentimento de constrangimento por reduzir a genialidade de Dostoevsky a um inventário de traços de personalidade.

As páginas de 0 Idiota são um testemunho eloqüente de como as vicissitudes de uma vida sofrida - a dura disciplina do pai, o confinamento na Sibéria, as dificuldades financeiras, a epilepsia, a tuberculose, as mortes da esposa e de dois filhos (um dos quais devido a status epilepticus) - foram transcendidas pela sensibilidade e pelo brilho de um gênio que deu à humanidade um dos mais sublimes panoramas do pensamento e da alma humanos.

Agradecimentos - Agradecemos ao Prof. Sebastião Nataniel da Silva Gusmão e ao Dr. Rodrigo Santiago Gomez pelos preciosos estímulo e orientação na redação deste artigo. Somos profundamente gratos a Davi Cabral, a Joana Cruz, a Lino Neto, a Mário Carlos Ribeiro, à Dra. Rachel Ferreira e a Reinaldo Cazotti Jr. pelo inestimável apoio recebido durante a realização deste trabalho, o qual thes é comovidamente dedicado.

\section{REFERÊNCIAS}

1. Alajounine T. Dostoiewski's epilepsy. Brain, 1963;86:(2):June.

2. Ozer IJ. Images of epilepsy in literature. Epilepsia, 1991;32:798-809.

3. Devinsky O, Najjar S. Evidence against the existence of a temporal lobe epilepsy syndrome. Neurology, 1999; 53 (Suppl 2).

4. Kraepelin E. Psychiatrie. 8.Ed. Lepizig: Barth, 1923.

5. Gibbs FA. Ictal and non-ictal psychiatric disorders in temporal lobe epilepsy. J Nerv Ment Dis 1951;113:522-528.

6. Gastaut H, Morin G, Leserve N. Étude du comportement des épileptiques psycho-moteurs dans l'intervalle de leurs crises. Ann Méd Psychol 1955;113:1-27.

7. Waxman SG, Geschwind N. The interictal behavior syndrome of temporal lobe epilepsy. Arch Gen Psychiatry 1975;32:1580-1586.

8. Bear DM, Fedio P. Quantitative analysis of interictal behavior in temporal lobe epilepsy. Arch Neurol 1977;4:454-467.

9. Csernansky JG, Leiderman DB, Mandabach M, Moses JA Jr. Psychopathology and limbic epilepsy: relationship to seizure variables and neuropsychological function. Epilepsia, 1990;31:275-280.

10. Rodin E, Schmaltz S. The Bear-Fedio personality inventory and temporal lobe epilepsy. Neurology, 1984;34:591-596.

11. Geschwind N. Interictal behavioral changes in epilepsy. Epilepsia, 1983;24:(Suppl 1):S23-S30.

12. Blumer D. Evidence supporting the temporal lobe epilepsy personality syndrome. Neurology 1999;53:(Suppl 2).

13. Weiser HG. Selective amygdalohippocampectomy: indications, investigative tecnique and results. Adv Tech Stand Neurosurg 1986;13:39133.

14. Trevisol-Bittencourt PC, Troiano AR. Síndrome de personalidade interictal na epilepsia do lobo temporal não-dominante. Arq Neuropsiquiatr 2000;58:548-555.

15. Gastaut H. Fyodor Mikhailovitch Dostoevsky's involuntary contribution to the symptomatolgy and prognosis of epilepsy. Epilepsia, 1978;19:186201.

16. Morgan H. Dostoevsky's epilepsy: a case report and comparison. Surg Neurol 1990;33:413-416.

17. Voskuil PHA. The epilepsy of Fyodor Mikhailovitch Dostoevsky (18211881). Epilepsia 1983;24:658-667.

18. Gastaut H. New comments on the epilepsy of Fyodor Dostoevsky. Epilepsia 1984;25:408-411.

19. Yacubian E. M. T. Costa Pinto G. R. S. Arte, poder, epilepsia. 2.Ed. São Paulo: Lemos Editorial, 2003. 
20. Cirignotta F, Todesco CV, Lugaresi E. Temporal lobe epilepsy with ecstatic seizures (so-called Dostoevsky epilepsy): case Report. Epilepsia 1980;21:705-710.

21. Amâncio EJ, Zymberg ST, Pires MFC. Epilepsia do lobo temporal e aura com alegria e prazer: relato de dois casos e revisão de literatura. Arq Neuropsiquiatr 1994;52:252-259.

22. Cabrera-Valdivia F, Jiménez-Jiménez FJ, Tejerio J, Ayuso-Peralta I, Vaquero A, Garcia-Albea E. Dostoevsky's epilepsy induced by television. J Neurol Neurosurg Psychiatry 1996;61:653.

23. Tanuri FC, Thomaz RB, Tanuri JA. Epilepsia do lobo temporal com aura do prazer: relato de caso. Arq Neuropsiquiatr 2000;58:178-180.

24. Dostoéivski, Fiódor. O Idiota. Tradução de Paulo Bezerra, desenhos de Oswaldo Goeldi. São Paulo: Ed. 34, 2002.

25. Dostoiévski: obra completa. Versão anotada, de Natália Nunes e Oscar Mendes. Rio de Janeiro Ed Nova Aguilar, 1995.

26. Dostoievskaia, Anna Grigorivena. Meu marido Dostoeivski. Tradução de Zoia Prestes. Rio de Janeiro Ed Mauad, 1999.

27. Frank J. Dostoiévski: as sementes da revolta (1821 a 1849). São Paulo, Edusp, 1999.

28. Frank J. Dostoiévski: os anos de provação (1850 a 1859). São Paulo: Edusp, 1999.

29. Frank J. Dostoiévski: os efeitos da libertação (1860 a 1865). São Paulo: Edusp, 2002.

30. Freud S. Obras completas. Madri: Biblioteca Nueva, 1996. 